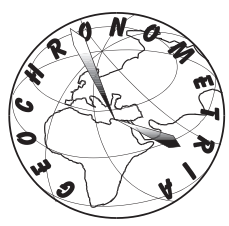

\title{
INVESTIGATIONS ON THE LUMINESCENCE PROPERTIES OF QUARTZ AND FELDSPARS EXTRACTED FROM LOESS IN THE CANTERBURY PLAINS, NEW ZEALAND SOUTH ISLAND
}

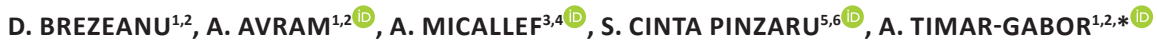 \\ ${ }^{1}$ Faculty of Environmental Science and Engineering, Babes-Bolyai University, Cluj-Napoca, Romania \\ ${ }^{2}$ Interdisciplinary Research Institute on Bio-Nano-Sciences, Environmental Radioactivity and Nuclear Dating Centre, \\ Babes-Bolyai University, Cluj-Napoca, Romania \\ ${ }^{3}$ Helmholtz Centre for Ocean Research, GEOMAR, Kiel, Germany \\ ${ }^{4}$ Marine Geology \& Seafloor Surveying, Department of Geosciences, University of Malta, Malta \\ ${ }^{5}$ Biomolecular Physics Department, Babes-Bolyai University, RO-400084 Cluj-Napoca, Romania \\ ${ }^{6}$ RDI Laboratory of Applied Raman Spectroscopy, RDI Institute of Applied Natural Sciences (IRDI-ANS), \\ Babeş-Bolyai University, Fântânele 42, RO-400293, Cluj-Napoca, Romania
}

Received 30 September 2020 Accepted 18 March 2021

\begin{abstract}
The applicability of the single-aliquot regenerative-dose (SAR) protocol, by using the optically stimulated luminescence (OSL) signal of quartz as well as the post-infrared-infrared (pIRIR) signals of polymineral fine grains, namely pIRIR ${ }_{225}$ and pIRIR ${ }_{290}$, was assessed for dating loess in New Zealand South Island. OSL signals of quartz grains displayed low sensitivity. However, the application of repeated irradiation/bleaching cycles did not result in an increase in sensitivity; annealing in the $300-500^{\circ} \mathrm{C}$ temperature range generated the sensitisation of both the $110^{\circ} \mathrm{C}$ thermoluminescence (TL) peak as well as the OSL signal, likely by activation of yet unidentified luminescence centres. After heating, the quartz signal is comparable to that of ideal samples, but the annealing is precluding successful dating. On the other hand, feldspar infrared-stimulated signals displayed satisfactory properties, allowing estimation of ages ranging from 14 $\pm 1-29 \pm 3$ ka for the investigated deposit. It was shown that pIRIR ${ }_{225}$ and pIRIR ${ }_{290}$ methods have potential for dating loess in the South Island of New Zealand, based on the following observations: (i) Dose recovery tests were successful with recovered-to-given dose ratios with a $<10 \%$ deviation from unity, (ii) constant residual values of about $4 \mathrm{~Gy}$ and about $10 \mathrm{~Gy}$ were obtained after exposures for $48 \mathrm{~h}$ in the case of pIRIR ${ }_{225}$ signals and $96 \mathrm{~h}$ in the case of pIRIR ${ }_{290}$ signals, respectively, (iii) while a slight dose-dependence of the residual was reported, and for a dose as large as $1600 \mathrm{~Gy}$ the residual values are $\cong 9$ Gy and $\cong 19$ Gy for pIRIR 225 and pIRIR ${ }_{290}$ signals, respectively.
\end{abstract}

Keywords

quartz, feldspar, luminescence, sensitivity, loess, New Zealand

\section{Introduction}

A well-established high-resolution chronology from southern mid-latitude sites is needed for providing a consistent framework of the inter-hemispheric climate changes. Archives in New Zealand play an important role for palaeo-climate reconstruction in the Southern Hemisphere (Alloway et al., 2007). Loess deposits represent one of the most widespread Quaternary archives in New Zealand, as they are estimated to cover approximately $10 \%$ of the land surface (Eden and Hammond, 2003; Yates et al., 2018).

Despite the well-established chronology of the North Island, there are few dating studies on the South Island of New Zealand. It was shown that some of the Quaternary dating methods have partial or no utility for chronological studies on loess-paleosol deposits from South Island. The current situation is that in addition to the fact that radiocarbon dating has a limited age range, previous studies 
have shown that both organic material and charcoal that is interbedded within loess may be contaminated by younger mobile organic compounds (Goh et al., 1978; Hammond et al., 1991). In later studies, Hormes et al. (2003) concluded that the radiocarbon ages reported by Almond et al. (2007) for Birdlings Flat loess at Ahuriri Quarry, Banks Peninsula, are inconsistent with the optically stimulated luminescence (OSL) ages as well as with the isochrone established by Kawakawa tephra. The variations recorded in magnetic susceptibility on loess paleosol sequences are usually allowing for secure correlations with marine isotope stages (MIS) chronology, as the signal is influenced by the climatic conditions. However, for soils in areas such as the eastern part of the South Island, where the mean annual rainfall is less than $1200 \mathrm{~mm}$, Pillans $(1991,1994)$ concluded that fluctuations recorded in the magnetic susceptibility are shielded due to iron remobilisation. For Canterbury, the mean annual rainfall is $645 \mathrm{~mm}$. Widespread tephra bed layers can play a crucial role for establishing chronological frameworks, but because of the long distance from the volcanic sources in North Island, South Island is poor in tephra marker horizons, with only two widespread tephra marker layers recognized in the loess deposits: the Aokautere Ash Member of Kawakawa Tephra Formation $(22,590 \pm 230 \mathrm{yr}$ BP, ca. 26,500 cal. yr BP - Wilson et al., 1988), identified in the upper loess units throughout most of South Island (e.g. Campbell, 1986, Eden et al., 1992; Almond et al., 2007) and the Rangitawa Tephra, dated at $\cong 340 \mathrm{ka}$ (Kohn et al., 1992; Alloway et al., 1993; Plillans 1996) and detected only by microscopic grain counting (Eden et al., 1992).

The OSL dating method has been successfully applied on quartz and feldspars extracted from various sediments on both the Northern and Southern Hemisphere during the last decades. The precision and the accuracy of the ages obtained have increased due to the development of the single-aliquot regenerative-dose (SAR) protocol on quartz (Murray and Wintle, 2000, 2003), as well as the versions of the protocol developed for feldspars, especially the post-infrared-infrared protocols (pIRIR), pIRIR $_{225}$ (Buylaert, 2009) and pIRIR 290 (Thiel, 2011). However, relatively few luminescence dating studies have been reported on sediments of various origins from South Island, New Zealand (e.g. Berger et al., 2001, 2002; Hormes et al., 2003; Litchfield and Lian 2004; Preusser et al., 2005; Almond et al., 2007; Rowan et al., 2012; Sohbati et al., 2016). For dating relatively young sediments, the preferred natural dosimeter is quartz, due to the higher bleachability of the signal. However, there are a few studies that reported luminescence ages using quartz (e.g. Holdaway et al., 2002; Nichol et al., 2003; Litchfield and Rieser, 2005; Rowan et al., 2012), and there is evidence that quartz from South Island suffers from major problems that limit its application, namely the weak sensitivity of the signal, with the signal apparently arising from many dim grains and the unsatisfactory behaviour in the SAR protocol (Preusseur et al., 2006). The recent developments of the pIRIR protocols based on the SAR procedure have increased the interest in using feldspars. While a number of studies reported the use of the infrared-stimulated luminescence (IRSL) dating method on coarse-grained K-rich feldspars (Preusseur et al., 2005) or on polymineral fine grains (e.g. Berger et al., 2001, 2002; Hormes et al., 2003; Rother et al., 2009; Almond et al., 2001, 2007; Shulmeister et al., 2010), the potential of the pIRIR protocols for dating sediments in South Island was not fully explored. To our knowledge, the only exceptions are the studies conducted by Sohbati et al. (2016) and Borella et al. (2016), which have applied the pIRIR $_{290}$ method on K-rich feldspars extracted from palaeo-rockfall boulders and loessic deposits south of Christchurch.

The aim of this study is to further explore the luminescence properties of quartz extracted from a loess deposit from Canterbury Plains, in the South Island, and to assess the applicability of two pIRIR stimulated luminescence protocols on polymineral fine grains extracted from the same samples.

\section{Study Site}

Apart from the Ross (2.4-2.6 Ma) and Porika (2.1-2.2 Ma) glaciations, New Zealand has undergone at least five glaciations during the Quaternary (Suggate, 1990). The most extensive deposits of loess are located across the foothills of the Southern Alps and in the lowlands of the Canterbury Plains (Yates et al., 2018). The most developed loess deposits, reaching a thickness of $>20 \mathrm{~m}$, are located on the lowlands south of Timaru (south Canterbury) and on Banks Peninsula (Bell and Trangmar, 1987). Based on mineralogical composition, the main source material for loess deposits from Canterbury Plains is eroded from the Southern Alps (Raeside, 1964; Sparrow, 1948; Young, 1964). Using thermoluminescence (TL), Berger et al. (2001) dated loess deposits from the south Canterbury Plains and Banks Peninsula, reporting ages ranging from $246 \pm 91 \mathrm{ka}$ (oldest age reported for Barrys Bay) to $21.4 \pm 2 \mathrm{ka}$ (youngest age reported for Cust section).

The study site $\left(44.018870^{\circ} \mathrm{S}, 171.882054^{\circ} \mathrm{E}\right)$ is located in the southern Canterbury Plains, on the eastern side of central South Island (Fig. 1). Modern Rakaia, Ashburton and Rangitata rivers flow perpendicularly to the eastern coastal cliff in the Canterbury Plains, discharging into the Pacific Ocean. The coastline at the study site consists of a steep cliff, up to $\mathrm{m}$ high and comprises poorly sorted and uncemented matrix-supported outwash gravel that is 


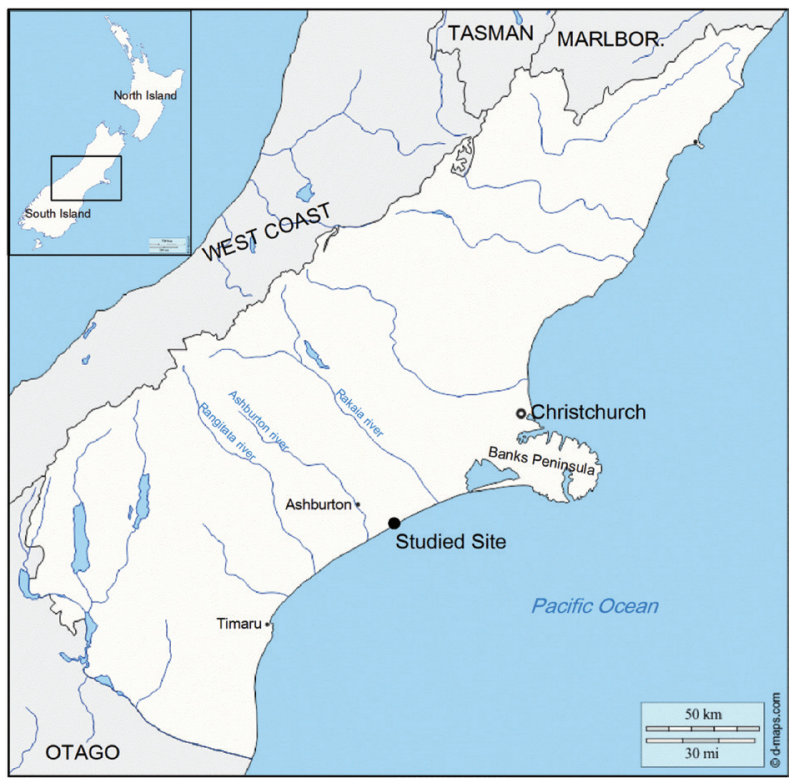

Fig 1. The map of the Canterbury Plains. The studied site is represented by filled circle (map source: www.d-maps.com).

capped by a few metres of loess and modern soil. The cliff is eroded by a series of wide coastal gullies (locally known as dongas). The sampling site is located halfway between Rakaia and Ashburton rivers, on the southern flank of one of these coastal gullies.

For luminescence investigations, five samples were collected from the top section of the flank. The uppermost sample was discarded from the analysis due to its proximity to the modern disturbed surface. The uppermost three samples analysed (NZ 2, NZ 3 and NZ 4) were collected at depths of $30 \mathrm{~cm}, 50 \mathrm{~cm}$ and $70 \mathrm{~cm}$, whereas the last sample (NZ 5) was collected from a depth of $140 \mathrm{~cm}$. According to Berger et al. (2001), they are expected to belong to L1 unit.

\section{Methodology}

\subsection{Sample Preparation}

Luminescence samples were collected in stainless steel tubes and were prepared under subdued red-light laboratory conditions. The material from the end of each tube was removed and used for gamma spectrometry measurements. The material from the inner part of the tubes was used for 63-90 $\mu \mathrm{m}, 90-125 \mu \mathrm{m}, 125-180 \mu \mathrm{m}, 180-250 \mu \mathrm{m}$ quartz and 4-11 $\mu \mathrm{m}$ polymineral grains' extraction. Treatments with hydrochloric acid (10\% concentration) and hydrogen peroxide $(10 \%$ concentration followed by $30 \%)$ were employed for calcium carbonate and organic matter removal. Finer $(<63 \mu \mathrm{m})$ and coarser $(>63 \mu \mathrm{m})$ grains were separated through wet sieving. Polymineral fine grains $(4-11 \mu \mathrm{m})$ were separated from the finer polymineral fraction obtained after Stoke's law, settling and centrifuging in distilled water (Frechen et al., 1996; Lang et al., 1996). The coarser (63-90 $\mu \mathrm{m}, 90-125 \mu \mathrm{m}, 125-180 \mu \mathrm{m}$ and 180-250 $\mu \mathrm{m}$ ) grain fractions were obtained by dry sieving. To isolate the coarse quartz fraction from the polymineral mixture, a density separation using heavy liquid was performed (2.62 and $2.75 \mathrm{~g} / \mathrm{cm}^{3}$ ). To remove any remaining feldspars and the outer alpha-irradiated portion of grains, the quartz-rich fraction was obtained by etching with hydrofluoric acid ( $40 \%$ concentration for $40 \mathrm{~min}$ ) followed by a rinse with hydrochloric acid (10\%) for 60 minutes to dissolve any insoluble fluorides that may have formed. For luminescence measurements polymineral fine grains were mounted on aluminium discs, whereas for coarse quartz stainless steel discs were used.

\subsection{Analytical Facilities}

All luminescence measurements were carried out using two Risø TL/OSL readers (model DA-20), equipped with a classic or automated detection and stimulation head (DASH) (Lapp et al., 2015). EMI 9235QA and PSM 9107Q-AP-TTL-03 (160-630 nm) photomultipliers were used for luminescence signals detection. Quartz signals were detected using a 7.5-mm-thick Hoya U-340 UV filters, while for polymineral fine grain signals a blue filter combination (Schott BG3 + Corning 7-59, with transmission between 320-460 nm) was used. Beta irradiations were carried out by ${ }^{90} \mathrm{Sr}-{ }^{90} \mathrm{Y}$ radioactive sources mounted on the readers and calibrated for both fine and coarse fractions using gamma-irradiated calibration quartz (Hansen et al., 2015).

The natural luminescence signal of the polymineral fine grain aliquots used for bleaching experiments and residual dose measurements was erased by exposing the disks to window light under natural conditions in March (latitude $\left.46^{\circ} 47^{\prime} \mathrm{N}\right)$.

Raman spectra have been recorded using a Renishaw InVia Reflex Confocal Raman system with a Leica microscope using the $100 \times$ (NA 0.9) long working-distance objective. For excitation, a Cobolt DPSS laser emitting at $532 \mathrm{~nm}$ was employed. Wavenumbers' calibration has been achieved using the internal silicon standard. An edge filter was employed for removing the Rayleigh line and the spectra were recorded in the $50-1840 \mathrm{~cm}^{-1}$ range with $0.5 \mathrm{~cm}^{-1}$ resolution. The acquisition conditions were $1 \mathrm{~s}$ exposure, 1 accumulation and $100 \%$ of the output laser power $(\cong 200$ $\mathrm{mW})$. A Rencam CCD was employed for signal detection and data acquisition, and processing has been achieved using the WIRE 3.4 and Origin 9.2 software.

\subsection{Equivalent Dose Determination}

The single-aliquot regenerative-dose optically stimulated luminescence (SAR-OSL) protocol (Murray and Wintle 
2000,2003 ) was applied on coarse quartz grains. Full details on the protocol are given in Table S1A in Supplementary Material. Optical stimulation was carried out with blue light-emitting diodes for $40 \mathrm{~s}$ at $125^{\circ} \mathrm{C}$. For analysis, the signal integrated over the first $0.308 \mathrm{~s}$ was used after an early background subtraction from 1.69-2.30 s interval, unless otherwise mentioned. A preheat temperature of $220^{\circ} \mathrm{C}$ for $10 \mathrm{~s}$ and a cutheat (ramp heating) of $180^{\circ} \mathrm{C}$ were employed. At the end of each SAR cycle, a high temperature bleach of $280^{\circ} \mathrm{C}$ for $40 \mathrm{~s}$ was performed. To check the robustness of the SAR protocol, intrinsic tests (recycling and recuperation) were included in every measurement as well as infrared (IR) depletion tests (Duller, 2003).

Equivalent doses measured on polymineral fine grains were carried out by applying two elevated-temperature infrared-stimulation methods based on the SAR procedure and the pIRIR 225 (Buylaert et al., 2009; Wacha and Frechen, 2011; Vasiliniuc et al., 2012) (Table S1B in Supplementary Material) and pIRIR ${ }_{290}$ (Buylaert et al., 2011a, 2012; Thiel et al., 2011) (Table S1C in Supplementary Material) protocols. To reduce the signal susceptible to fading by allowing recombination of near-neighbour trap and centre pairs, a stimulation with IR diodes for $200 \mathrm{~s}$ at $50^{\circ} \mathrm{C}$ was performed after a preheat of $60 \mathrm{~s}$ at $250^{\circ} \mathrm{C}$ in the case of pIRIR 225 protocol and $320^{\circ} \mathrm{C}$ in the case of pIRIR 290 protocol, respectively. The signal of interest was recorded during a subsequent IR stimulation for $200 \mathrm{~s}$ at $225^{\circ} \mathrm{C}$ in the case of pIRIR $_{225}$ protocol and at $290^{\circ} \mathrm{C}$ in the case of pIRIR 290 protocol. The net signal used for analysis was integrated from the initial $2.5 \mathrm{~s}$ of stimulation minus a background evaluated from the last $50 \mathrm{~s}$. A high temperature bleach was performed for $100 \mathrm{~s}$ at $290^{\circ} \mathrm{C}$ (pIRIR ${ }_{225}$ protocol) and $325^{\circ} \mathrm{C}$ (pIRIR ${ }_{290}$ protocol) at the end of each cycle of measurements. The size of the test dose was 17 Gy for all measurements.

\subsection{Dosimetry}

High-resolution gamma spectrometry was applied to determine the radionuclide specific activities using a well-type HPGe detector. For ${ }^{226} \mathrm{Ra}^{-222} \mathrm{Rn}$ equilibrium to be reached, the samples were stored for 1 month before measurement. Annual dose rates were determined using the conversion factors tabulated by Guérin et al. (2011). An alpha efficiency factor of $0.08 \pm 0.02$ was considered for the 4-11 $\mu \mathrm{m}$ polymineral fraction (Rees-Jones, 1995). The time-averaged water content was assumed to be $15 \%$ with a relative error of $25 \%$. The water content was chosen to represent the mean water content over the depositional history of the sediments. Similar values for water content were used by Rowan et al. (2012) and Sohbati et al. (2016) for sediments from Canterbury Plains and Banks Peninsula, respectively. The external contribution from beta, gamma and alpha radiation, as well as from the cosmic background radiation, was included in the total dose rates. The cosmic dose rate was estimated as a function of depth, altitude and geomagnetic latitude (Prescott and Hutton, 1994).

\section{Results And Discussion}

\subsection{Luminescence Properties - Quartz}

We have checked the purity of the quartz mineral extracts and their crystallinity by conducting RAMAN spectroscopy on sample NZ 5 63-90 $\mu \mathrm{m}$. Fig. 2 compares the spectrum of the sample to that obtained on calibration quartz. The results confirm that our extracted material is indeed crystalline quartz, according to the characteristic sharp bands observed in all the recorded spectra, similar to the quartz calibration sample. The 15 bands - observed in the Raman spectra recorded with minimal acquisition time (1s) and 1 accumulation - resembled those observed by Krishnan since early Raman studies on quartz that were published (Krishnan, 1945). The observed bands from microcrystals are located at $128(\mathrm{~s}), 206(\mathrm{~s}), 265(\mathrm{~m}), 356(\mathrm{~m}), 394(\mathrm{~m})$, 404 (m), 452 (sh), 464 (vs), 696 (m), 793 (w), 804 (w), $1063(\mathrm{w}), 1082(\mathrm{w}), 1160(\mathrm{~m})$ and $1230 \mathrm{~cm}^{-1}(\mathrm{w})$.

To check if the quartz extracted from the investigated samples is suitable for OSL dating, the SAR-OSL protocol labelled in Table S1A in Supplementary Material was applied. Fig. 3A shows a typical OSL decay curve for the natural signal, while in Fig. 3B, the decay of the signal measured after a regenerative dose of $100 \mathrm{~Gy}$ is compared to that of calibration quartz. Based on the comparison to calibration quartz, it can be observed that the fast component does exist in the OSL signal. However, its intensity is very weak. All investigated grain sizes displayed low sensitivity, with no more than $1500 \mathrm{cts}$ recorded in the first $1.2 \mathrm{~s}$ of stimulation in the case of the natural signal (see Table S2 in Supplementary Material). A weak signal

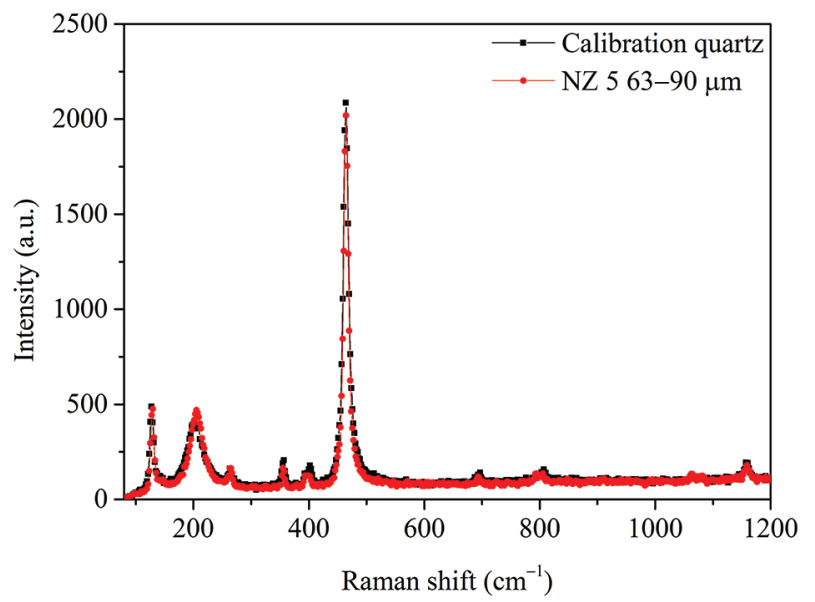

Fig 2. Comparison of calibration quartz (filled squares) RAMAN spectra with that of the 63-90 $\mu \mathrm{m}$ quartz (filled circles) extracted from sample NZ5. 

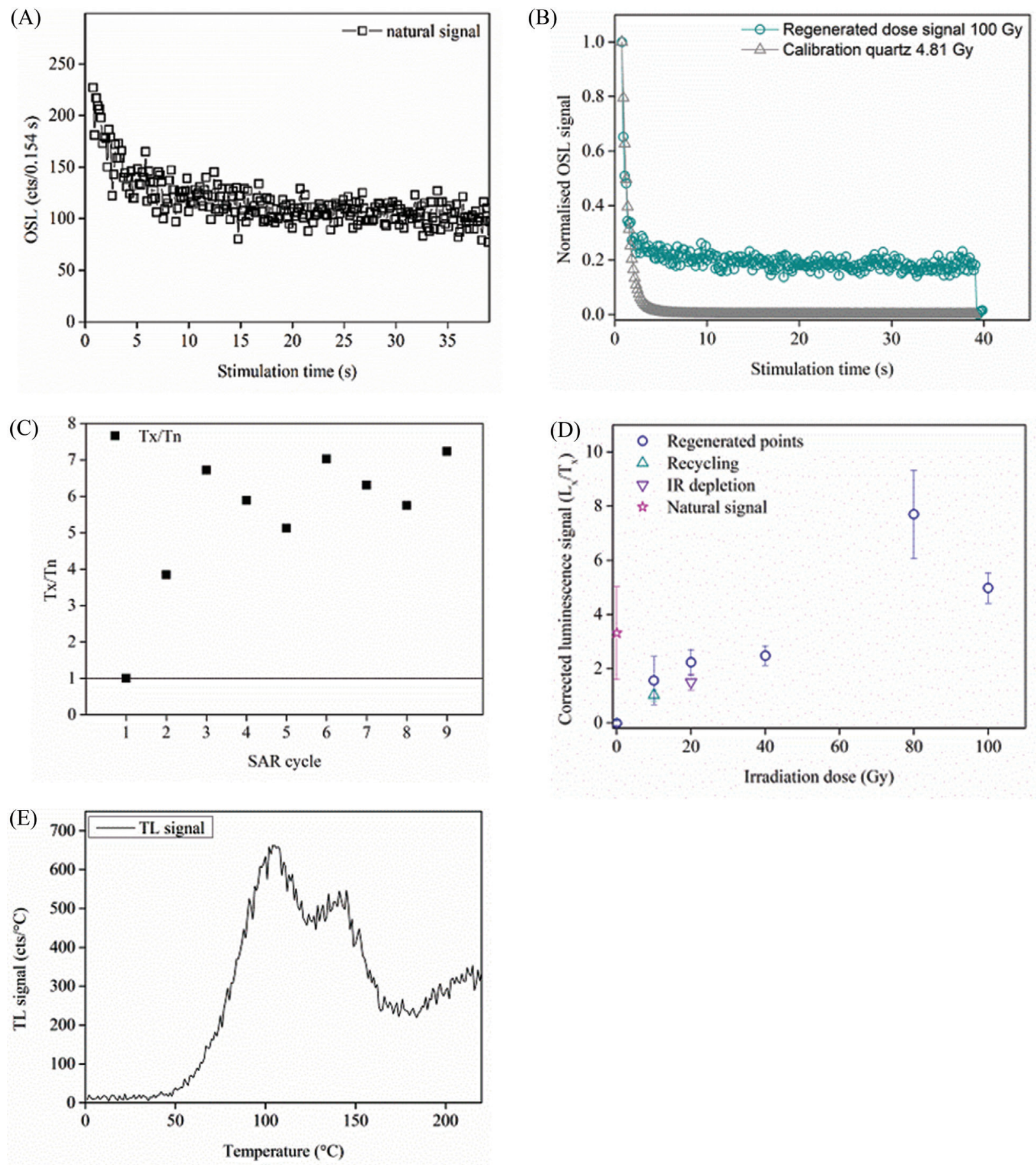

Fig 3. Representative luminescence behaviour of 63-90 $\mu \mathrm{m}$ quartz extracted from sample NZ 3. (A) the decay curve of natural continuous-wave optically stimulated luminescence (CW-OSL) signal (open squares); (B) comparison between the decay curve of a regenerated dose of $100 \mathrm{~Gy}$ (open circles) and the typical decay curve of a calibration quartz (open triangles); data is normalised to the number of counts collected in the first channel of stimulation; (C) variation of the TX/Tn ratio during SAR cycles; (D) representative sensitivity-corrected dose response curve. The sensitivity corrected natural signal is depicted as a star. Recycling and IR depletion points are represented as an upward triangle and inverse triangle, respectively; (E) TL signal recorded during the preheat to $220^{\circ} \mathrm{C}$ employed in a typical SAR cycle after irradiation with a regenerative dose of $100 \mathrm{~Gy}$. SAR, single-aliquot regenerative-dose; $T L$, thermoluminescence. 
could result in obtaining an equivalent dose of low precision, but it should not affect the accuracy of the result. As the signals were found to be above the detection limit, we have attempted to apply the SAR protocol to the various grain sizes of quartz that were available. However, significant sensitivity changes were observed to occur. The response to the administered test dose was found to vary significantly from one cycle to another, the response increasing significantly during measurement cycles as indicated by Fig. 3C. The SAR protocol is not able to correct for sensitivity changes and a well-defined dose response curve could not be constructed; an example of this can be observed in Fig. 3D. Consequently, equivalent doses could not be confidently determined using quartz SAROSL. Another important observation was made while recording the TL signals during the preheat procedures applied in the SAR protocol following laboratory given doses. Unlike the case of well-behaved OSL samples, where well-defined $110^{\circ} \mathrm{C}$ TL peaks are always observed, the TL signals recorded for these samples displayed weak $110^{\circ} \mathrm{C}$ TL peaks along with a second peak at $150^{\circ} \mathrm{C}$. While the existence of the $150^{\circ} \mathrm{C}$ TL peak in quartz is well known (see e.g. Chruścińska et al., 1996, Veronese et al. 2004, Preusser et al., 2009) we have never identified it visually so far in samples that are displaying bright OSL signals due to the dominance of the $110^{\circ} \mathrm{C}$ TL peaks. Fig. $3 \mathbf{E}$ presents such a typical example for quartz from $\mathrm{New}$ Zealand for a heating rate of $5^{\circ} \mathrm{C} / \mathrm{s}$.

We have further tested the behaviour of sample NZ 3 63-90 $\mu \mathrm{m}$ quartz by performing a dose-recovery test. Three aliquots were bleached with blue diodes twice at room temperature for $100 \mathrm{~s}$ with a $10000 \mathrm{~s}$ pause in between the two stimulations. A dose of $100 \mathrm{~Gy}$ was then administered and measured as unknown, using the SAR protocol as described in Section 3.3. Table 1 summarises the results that were obtained. One can ascertain that an increase in sensitivity occurs and sensitivity changes are not properly corrected by the measurement protocol, as observed form recycling tests. This results in an unsatisfactory recovered-to-given dose ratio.

The failure of the quartz from New Zealand to accurately measure a given dose in the SAR protocol, as well as its poor OSL sensitivity, have been previously reported by
Preusser et al. (2006) for sedimentary quartz of metamorphic origin from the forefield of Franz Joseph Glacier in the western part of South Island. The above-mentioned study attributed this behaviour to the short sedimentary history of the grains, as it was reported that sensitisation of the OSL signal was achieved by repeated bleaching/irradiation cycles.

To test whether OSL properties of the samples investigated here can be improved by the application of different irradiation and stimulation steps, we have conducted a dose recovery test on sample NZ $363-90 \mu \mathrm{m}$ under the same conditions as presented above, except that the whole procedure was carried out subsequent to the application of three different treatments:

(i) the repetition of 5 bleach (blue diodes stimulation for $100 \mathrm{~s}$ at room temperature)/dose (100 Gy) cycles,

(ii) irradiating the sample with a dose of 100 Gy followed by heating to $500^{\circ} \mathrm{C}$ five times and

(iii) simply by repeating five times the heat treatment that consistied of a ramp heating to $500^{\circ} \mathrm{C}$. The results of the dose recovery test performed following these treatments are presented in Table 2.

Contrary to the findings of Preusser et al. (2006), we have not observed an increase in sensitivity or an improvement in the results of the dose recovery test - in other words, a better behaviour of the material in the SAR protocol in accordance with the following treatment, namely (i) the application of repeated bleach/dose cycles. However, the sensitivity is increased by one order of magnitude following dosing and annealing, with the heat treatment accounting for most of the effect, as can be seen from the results of experiment (ii) where irradiations have not been carried out. Following the application of the annealing to $500^{\circ} \mathrm{C}$, the behaviour of the OSL signals in the SAR protocol is improved, with satisfactory recycling and dose recovery tests results (Table 2).

Another important observation is that significant sensitisation of the $110^{\circ} \mathrm{C}$ TL signals was observed following annealing to $500^{\circ} \mathrm{C}$ (Fig. S1 and Fig. S2 in Supplementary Material). During experiment (ii) presented above, it was observed that, while the $110^{\circ} \mathrm{C}$ peak is weak in intensity

Table 1. Results of dose recovery tests on NZ 3 63-90 $\mu \mathrm{m}$ quartz.

\begin{tabular}{|c|c|c|c|c|c|c|c|}
\hline & $\begin{array}{l}\text { Signal sensitivity for } \\
\text { the dose to be recov- } \\
\text { ered (cts in } 1.2 \mathrm{~s} \text { ) }\end{array}$ & $\begin{array}{l}\text { Average signal sensi- } \\
\text { tivity (cts in } 1.2 \mathrm{~s} \text { ) for } \\
\text { dose to be recovered }\end{array}$ & $\begin{array}{c}\text { Signal sensitivity } \\
\text { for } 100 \text { Gy in SAR } \\
\text { (cts in } 1.2 \mathrm{~s} \text { ) }\end{array}$ & $\begin{array}{c}\text { Average } \\
\text { signal sensitivity } \\
\text { for } 100 \mathrm{~Gy} \text { in } \\
\text { SAR (cts in } 1.2 \mathrm{~s} \text { ) }\end{array}$ & Recycling ratio & IR depletion ratio & Recovered/given dose \\
\hline aliq 1 & 3789 & $2571 \pm 684$ & 6268 & $4472 \pm 930$ & 1.13 & 0.78 & 0.81 \\
\hline aliq 2 & 1422 & & 3154 & & 0.83 & 0.76 & 0.60 \\
\hline aliq 3 & 2502 & & 3993 & & 1.11 & 0.78 & 0.94 \\
\hline
\end{tabular}

IR, infrared. 
Table 2. Results of dose recovery tests after repeated cycles of bleaching and irradiation and heating and irradiation.

\begin{tabular}{|c|c|c|c|c|c|c|c|c|}
\hline $\begin{array}{l}\text { Treatment } \\
\text { applied be- } \\
\text { fore the dose } \\
\text { recovery test }\end{array}$ & Aliq No. & $\begin{array}{l}\text { Signal sensi- } \\
\text { tivity for the } \\
\text { dose to be } \\
\text { recovered } \\
\text { (cts in } 1.2 \mathrm{~s} \text { ) }\end{array}$ & $\begin{array}{l}\text { Average signal sen- } \\
\text { sitivity for the dose } \\
\text { to be recovered (cts } \\
\text { in } 1.2 \mathrm{~s} \text { ) }\end{array}$ & $\begin{array}{l}\text { Signal sensitivity } \\
\text { for } 100 \text { Gy in SAR } \\
\text { (cts in } 1.2 \mathrm{~s} \text { ) }\end{array}$ & $\begin{array}{c}\text { Average signal } \\
\text { sensitivity for } \\
100 \mathrm{~Gy} \text { in SAR } \\
\text { (cts in } 1.2 \mathrm{~s} \text { ) }\end{array}$ & $\begin{array}{l}\text { Recycling } \\
\text { ratio }\end{array}$ & $\begin{array}{l}\text { IR depletion } \\
\text { ratio }\end{array}$ & Recovered/given dose \\
\hline \multirow{3}{*}{$\begin{array}{l}\text { Experiment (i) } \\
\text { Bleach/dose } \\
(100 \mathrm{~Gy}) \times 5\end{array}$} & 1 & 2685 & $2858 \pm 718$ & 2869 & $3015 \pm 565$ & 1.06 & 1.23 & 0.91 \\
\hline & 2 & 1710 & & 2119 & & 1.14 & 0.89 & 0.66 \\
\hline & 3 & 4180 & & 4058 & & 0.82 & 0.57 & 1.08 \\
\hline \multirow{3}{*}{$\begin{array}{l}\text { Experiment } \\
\text { (ii) Heat to } \\
500^{\circ} \mathrm{C} / \text { dose } \\
(100 \mathrm{~Gy}) \times 5\end{array}$} & 1 & 34665 & $49960 \pm 12765$ & 41173 & $60220 \pm 16152$ & 1.00 & 0.97 & 0.94 \\
\hline & 2 & 39905 & & 47148 & & 0.98 & 1.01 & 0.95 \\
\hline & 3 & 75311 & & 92339 & & 1.00 & 0.99 & 0.92 \\
\hline \multirow{2}{*}{$\begin{array}{l}\text { Experiment } \\
\text { (iii) Heat to }\end{array}$} & 1 & 10406 & $20287 \pm 6244$ & 11556 & $25794 \pm 8760$ & 0.98 & 0.99 & 0.97 \\
\hline & 2 & 18612 & & 24073 & & 1.02 & 0.98 & 0.92 \\
\hline $500^{\circ} \mathrm{C} \times 5$ & 3 & 31842 & & 41754 & & 0.98 & 1.01 & 0.94 \\
\hline
\end{tabular}

IR, infrared.

during the first TL recorded (Fig. S2A in Supplementary Material), once the sample was heated to $500^{\circ} \mathrm{C}$, the TL glow-curve shape changes dramatically. In the second TL/ dose measurement cycle the $110^{\circ} \mathrm{C}$, the TL peak is well represented, and the glow curve is repetitive during subsequent irradiation read-out steps in the annealing process (Fig. S2B in Supplementary Material). In the case of the dose recovery test without previous annealing, a composite $110-150^{\circ} \mathrm{C}$ peak is observed in the low temperature region during the preheat of the signals (Fig. S2C in Supplementary Material), and the OSL signals are weak in intensity (Fig. S2E in Supplementary Material). If the sample is annealed to $500^{\circ} \mathrm{C}$ before the dose recovery test, the OSL signals increase by one order of magnitude (Fig. S2F in Supplementary Material) and so does the $110^{\circ} \mathrm{C}$ TL peak (Fig. S2D in Supplementary Material). Annealing the sample to $500^{\circ} \mathrm{C}$ results in the sensitisation of both the $110^{\circ} \mathrm{C}$ TL peak as well as the OSL fast component. While the heat treatment is making the quartz signal comparable to that employed in standard OSL dating, the annealing removes the desirable natural signal, precluding successful dating of the material.

The effect of repeating the annealing cycles on the OSL signal is shown in Fig. 4 for the response of sample NZ $363-90 \mu \mathrm{m}$ quartz to a dose of $100 \mathrm{~Gy}$. The sample was bleached (room-temperature blue-diode stimulation for $100 \mathrm{~s}$, pause of $10000 \mathrm{~s}$, room-temperature blue-diode stimulation for $100 \mathrm{~s}$ ) and then subjected repeatedly to the following measurement cycle: irradiation (100 Gy), preheat for $10 \mathrm{~s}$ to $220^{\circ} \mathrm{C}$, OSL measurement (blue diode stimulation at $125^{\circ} \mathrm{C}$ ), annealing (TL measurement) to $500^{\circ} \mathrm{C}$. Data presented in Fig. 4 show that the first thermal treatment enhances the sensitivity by one order of magnitude and subsequent annealing treatments do not have a further significant effect.
The effect of varying the annealing temperature was tested, as well. Aliquots of sample NZ 3 63-90 $\mu \mathrm{m}$ quartz were bleached and subjected to the following measurement steps: irradiation with $100 \mathrm{~Gy}$, preheat for $10 \mathrm{~s}$ at $220^{\circ} \mathrm{C}$, OSL measurement (for $40 \mathrm{~s}$ at $125^{\circ} \mathrm{C}$ ), anneal to $\mathrm{T}_{\mathrm{a}}$ (ramp heating to a temperature between $225^{\circ} \mathrm{C}$ and $525^{\circ} \mathrm{C}$ ), irradiation with $100 \mathrm{~Gy}$, preheat for $10 \mathrm{~s}$ at $220^{\circ} \mathrm{C}$, OSL measurement (for $40 \mathrm{~s}$ at $125^{\circ} \mathrm{C}$ ). The OSL response after annealing can be compared to the OSL response before the application of the thermal treatment. This was carried out on three aliquots for each anneal temperature employed and the results of the average ratio between the post annealing and pre-annealing signals are presented in Fig. 5.

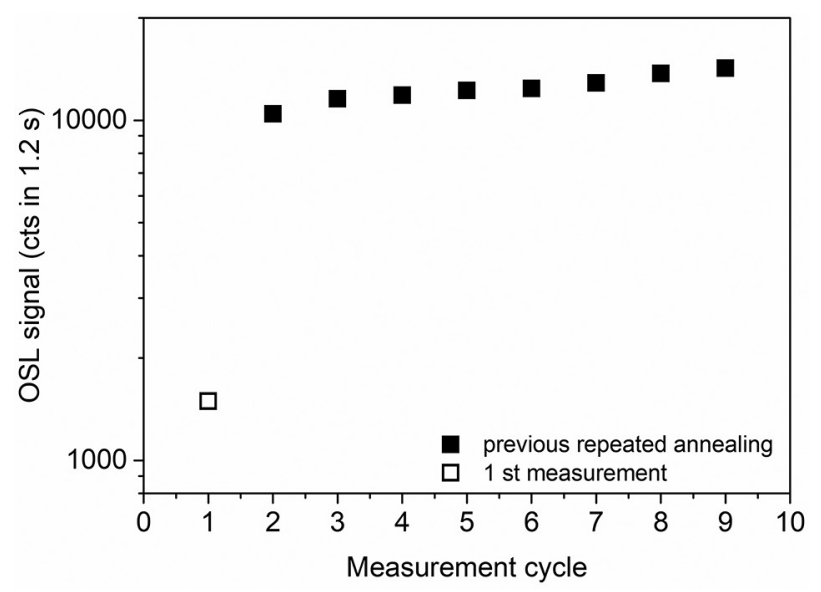

Fig 4. The OSL signal sensitisation after repeated annealing to $500^{\circ} \mathrm{C}$. The luminescence signal intensities were measured after an irradiation to $100 \mathrm{~Gy}$ and a preheat to $220^{\circ} \mathrm{C}$ for $10 \mathrm{~s}$. The OSL signal recorded before the first annealing is presented as an open square whereas the luminescence signals recorded following repeated annealing irradiation cycles are represented as solid squares. OSL, optically stimulated luminescence. 


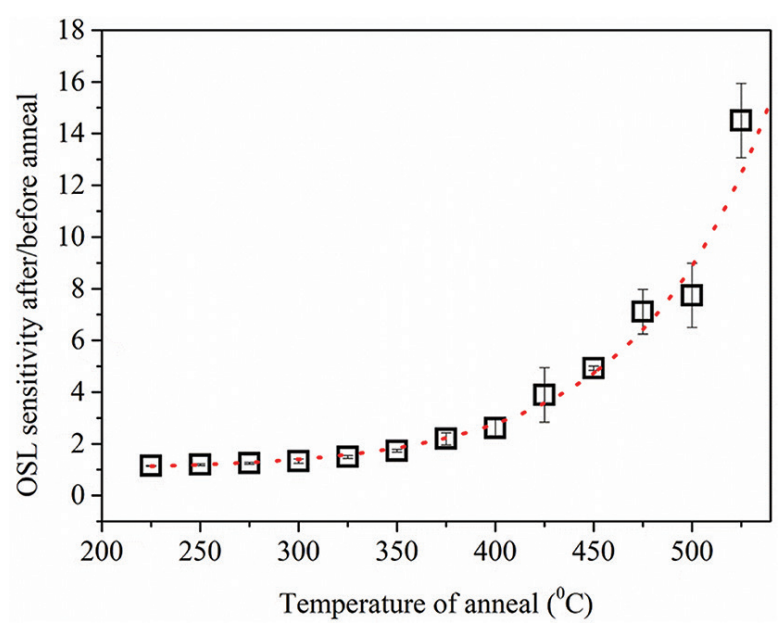

Fig 5. Sensitivity increase of the OSL signal as function of the annealing temperature. The dotted line represents an exponential dependence. OSL, optically stimulated luminescence.

An exponential increase is reported as a function of annealing temperature, significant sensitisation occurring for heating temperatures above $\cong 350^{\circ} \mathrm{C}$. This sensitisation with heating is intriguing, given the fact that the quartz analysed should have an important metamorphic (sub-greenschist) component from the Eastern greywacke basement rocks. For this reason, the crystal should have been subjected to moderate heating 300-100 Ma. Poor OSL properties of metamorphic quartz were also reported by Guralnik et al., 2015, with the authors inferring that only samples from a low-grade metamorphic context (heated to less than $\cong 380^{\circ} \mathrm{C}$ ) are displaying satisfactory OSL properties.

Sensitisation by heating, and not due to pre-dose activation, was previously reported to occur in partially fired (i.e. annealed only to moderate temperatures) quartz (Yang and McKeever, 1990; Bøtter-Jensen et al., 1995). However, a physical mechanism was not proposed as it was concluded that it is not possible to distinguish between a model that calls for the creation of luminescence centres or one that calls for the removal of non-luminescence centres due to annealing (Bøtter-Jensen et al., 1995). In a later multi spectroscopic study, Schilles et al., 2001 concluded that luminescence is generally sensitised in quartz by heating to $500^{\circ} \mathrm{C}$ or more by the removal of oxygen vacancy E'centres, which is considered as a luminescence competitor. This mechanism cannot account for the observations made here, as sensitisation is observed also in the 300 $400^{\circ} \mathrm{C}$ temperature range, where a heat treatment following irradiation is known to increase the intensity of E'centres (see e.g. Toyoda and Hattori, 2000).

The dependency presented is suggestive not only of the thermal activation curves presented by Yang and McKeever (1990) for their as-received Arkansas quartz, but also of the annealing temperature dependence of the $\mathrm{C}$ band $(3.4 \mathrm{eV})$ for radioluminescence signals reported by Martini et al. (2014) for natural quartz. Consequently, the results presented indicate that the heating process is most likely affecting the luminescence pathway and not the trapping process, by the creation of recombination centres. Investigations for gaining further understanding on these matters by employing electron spin resonance measurements are currently underway.

\subsection{Luminescence Properties - Polymineral Grains}

\subsubsection{Equivalent doses}

Unlike OSL signals of quartz, the IRSL signals of polymineral fine grains displayed a satisfactory behaviour in the SAR protocol. Equivalent doses were obtained by interpolating the natural sensitivity corrected luminescence signal on the dose response curve constructed for each sample using both pIRIR protocols. Fig. 6 shows a representative growth curve for sample NZ 4 using pIRIR $_{225}$ (Fig. 6A) and the pIRIR ${ }_{290}$ (Fig. 6B) protocols, respectively. The insets of Fig. 6 present the comparison of decay curves of the natural signals to those measured following regenerative doses.

The dose response curves were best fitted by a sum of two saturating exponential functions. The values for the equivalent doses range from $64 \pm 2$ Gy to $92 \pm 23$ Gy in the case of pIRIR $_{225}$ protocol and from $83 \pm 3$ Gy to $120 \pm 6$ Gy in the case of pIRIR ${ }_{290}$ protocol, respectively. The measured equivalent doses along with the results of recycling and recuperation tests for each sample are shown in Table S3 in Supplementary Material.

\subsubsection{Residual signals}

It is well known that the post-IR IRSL signals are difficult to bleach, as residual doses of a few grays have been reported even after prolonged exposure to daylight or light in a solar simulator (e.g Buylaert et al., 2011b, 2012; Stevens et al., 2011; Murray et al., 2012, 2014; Yi et al., 2016, 2018; Sohbati et al., 2016; Veres et al., 2018; Avram et al., 2020). Also, by measuring samples of modern dust and samples with an equivalent dose $<1$ Gy collected from Chinese Loess Plateau, Buylaert et al. (2011b) have reported a residual average dose of 4 Gy for pIRIR $_{225}$ protocol and 11 Gy when using the pIRIR ${ }_{290}$ protocol.

To quantify residual values, four fresh aliquots from each sample were exposed to window for 30 days to remove the natural signal and quantify the residual level. Residual doses measured using the pIRIR $_{225}$ protocol range from $3.3 \pm 0.4$ Gy to $3.7 \pm 0.3 \mathrm{~Gy}$, while the values obtained using the pIRIR $_{290}$ protocol are from $4.1 \pm 0.6 \mathrm{~Gy}$ to $13.6 \pm 2.5$ Gy. The values obtained on each sample are presented in Table S4 in Supplementary Material and plotted against the measured equivalent dose in Fig. S3 in Supplementary Material. 
(A)

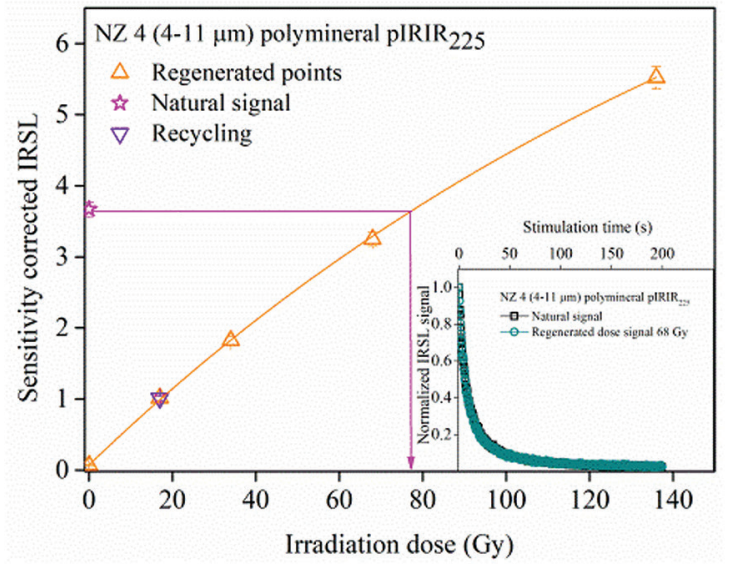

(B)

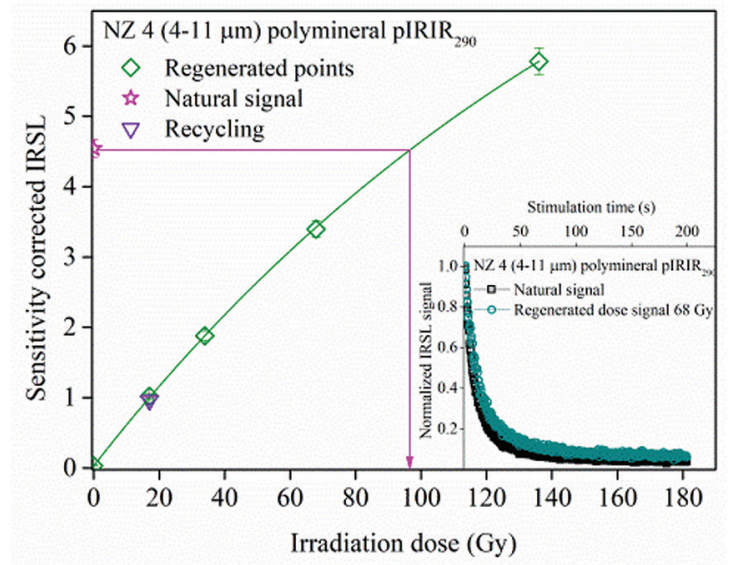

Fig 6. Representative sensitivity-corrected dose-response curves constructed for one aliquot from sample NZ 4 on polymineral fine (4-11 $\mu$ m) grains using (A) pIRIR ${ }_{225}$ and (B) pIRIR ${ }_{20}$ protocol. The sensitivity corrected natural signals are depicted as stars interpolated on the dose response curves for indicating the equivalent doses. The recycling point is represented as an inverse triangle. Insets show typical decay curves of natural CW-OSL signals (open squares) in comparison to a regenerated signals (open circles) induced by a beta dose approximately equal to the equivalent dose. pIRIR, post-infrared-infrared protocol.

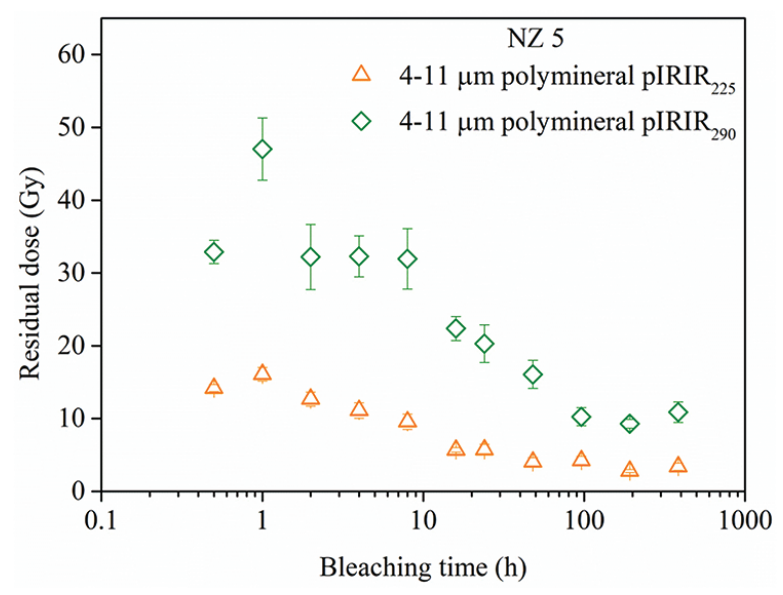

Fig 7. Residual doses measured using pIRIR $_{225}$ (upward triangle) and pIRIR $_{290}$ (diamond) after different bleaching times. The natural signal was bleached under natural conditions under window light. The shortest bleaching time was $0.5 \mathrm{~h}$ while the longest was $192 \mathrm{~h}$. pIRIR, post-infrared-infrared protocol.

To check whether this is indeed the minimum residual level that can be achieved as function of exposure time, sets of five fresh aliquots of sample NZ5 were exposed to window light for different periods of time (from $0.5 \mathrm{~h}$ to 192 h). The results are shown in Fig. 7. In the case of pIRIR $_{225}$ protocol, a constant residual dose of $3.7 \pm 0.5 \mathrm{~Gy}$ is achieved after $48 \mathrm{~h}$ of exposure, while in the case of the pIRIR $_{290}$, signals' residual values reach a constant value of $9.8 \pm 0.5$ Gy only after a bleaching time of $96 \mathrm{~h}$. These results are in line with the values obtained for the 30-day-experiment.

Several studies have reported that the magnitude of the residual dose is dependent on the equivalent dose (e.g. Sohbati et al., 2012; Buylaert et al., 2012, Yi et al., 2016), suggesting a possible dose dependency of the residual. For the different samples investigated here, the residual doses measured after 30 days of exposure do not differ significantly (Table S4 in Supplementary Material) and neither do the equivalent doses. To investigate whether the residual signal is dose dependent, eight bleached aliquots of samples NZ2, NZ3 and NZ 4 were irradiated with different beta doses of $400 \mathrm{~Gy}, 800 \mathrm{~Gy}$ and $1600 \mathrm{~Gy}$ and subsequently exposed to windowlight. After an exposure of 30 days, four aliquots from each sample were measured using pIRIR $_{225}$ protocol, whereas for the other four aliquots, the pIRIR ${ }_{290}$ protocol was used. The results are displayed in Fig. 8. An increase of the residual dose with the size of the previously given dose can be observed in the case of both pIRIR $_{225}$ and pIRIR $_{290}$ protocols. The magnitude of the residuals range from $5.9 \pm 0.7 \mathrm{~Gy}$ (for a dose of $400 \mathrm{~Gy}$ ) to $8.9 \pm 1 \mathrm{~Gy}$ (for a dose of $1600 \mathrm{~Gy}$ ) in the case of pIRIR $_{225}$ and from $13.9 \pm 1.2 \mathrm{~Gy}$ (for a dose of $400 \mathrm{~Gy}$ ) to $18.5 \pm 1.7 \mathrm{~Gy}$ (for a dose of $1600 \mathrm{~Gy}$ ) in the case of pIRIR $_{290}$, respectively.

We compare the data obtained for $1600 \mathrm{~Gy}(8.9 \pm 1 \mathrm{~Gy}$ for pIRIR $_{225}$ and $18.5 \pm 1.7 \mathrm{~Gy}$ for $\mathrm{pIRIR}_{290}$ ) to the values obtained in the bleaching experiment for the natural signals (corresponding to a measured equivalent dose of $\cong 60-120 \mathrm{~Gy}$ ), namely average values on all samples of $3.5 \pm 0.2$ Gy for pIRIR $_{225}$ and $9.2 \pm 2.0$ Gy for pIRIR $_{290}$, respectively. We conclude that (i) different doses accrued by the mineral grain before the bleaching event should not result in dramatically different residual doses and (ii) performing bleaching experiments on natural samples instead of using a modern analogue should not result in an offset of 
more than a few Grays. Bleaching corrections should not cause significant inaccuracies unless very young samples are dated. However, since a dose dependence is reported, and since it remains questionable whether the conditions in the laboratory fully reproduce the bleaching process in nature, it is advisable to measure a modern analogue for residual dose estimation, as well. Here, a modern sample was collected from a nearby site (latitude $44.014973^{\circ} \mathrm{S}$, longitude $171.891569^{\circ}$ E). Following the same methodology, an equivalent dose of $7.5 \pm 0.5$ Gy was measured using pIRIR 225 protocol; on the other hand, using pIRIR $_{290}$ protocol, a dose of $22.8 \pm 1.5$ Gy was obtained. Based on the results of the laboratory experiments presented above, we consider these residual doses as maximum values. We have chosen to perform residual corrections using both laboratory obtained values, as well as by the modern analogue approach (Table 3 ).

Uncertainties were determined following Aitken and Alldred (1972). A 15\% water content was assumed with a relative error of $25 \%$. Errors quoted on equivalent doses and specific activities represent random uncertainties. The uncertainties quoted for the ages represent total (random and systematic) errors computed in quadrature. pRIR, postinfrared-infrared protocols.

\subsubsection{Dose recovery}

To further check the reliability of the measurement protocol, a dose recovery test (Murray, 1996; Wallinga et al., 2000) was performed on five aliquots from each sample using both pIRIR protocols. The natural signal was bleached by exposing fresh aliquots to window for 1 month. The aliquots were subsequently irradiated with laboratory-known doses, chosen to approximate the measured equivalent dose. The dose recovery ratios were obtained by dividing the measured recovered dose by the value of the given dose. The measured residual doses were subtracted from the recovered dose prior to dose recovery ratio calculation. The results of the dose recovery tests using pIRIR 225 and pIRIR $_{290}$ protocols, respectively, are shown in Fig. 9.

Dose recovery ratios obtained for the pIRIR $_{225}$ protocol range from $0.97 \pm 0.02$ (NZ2) to $1.03 \pm 0.01$ (NZ 5), while for
pIRIR $_{290}$ they range from $1.02 \pm 0.04$ (NZ 2) to $1.09 \pm 0.05$ (NZ 3), suggesting that both pIRIR 225 and pIRIR ${ }_{290}$ protocols can successfully recover the laboratory doses given.

\subsubsection{Anomalous fading tests}

The greatest disadvantage of using feldspars as luminescence dosimeters is the loss of the signal during burial time. This loss of the signal is known as anomalous fading and can be usually quantified in terms of fading rates (percentage of the signal lost per decade; Aitken, 1985). Thiel et al. (2011) have reported for the first time a natural pIRIR $_{290}$ signal in saturation for a sample collected below the $\mathrm{B} / \mathrm{M}$ boundary and concluded that $\mathrm{pIRIR}_{290}$ signal is a stable signal and the pIRIR ${ }_{290}$-ages do not need any further fading correction. Similar observations have been made by other researchers for pIRIR ${ }_{290}$ protocol on both polymineral fine grains and K-feldspars (e.g. Buylaert et al., 2011b; Thomsen et al., 2011; Veres et al., 2018; Avram et al., 2020). Based on laboratory fading experiments, other studies reported fading rates of $<1 \% /$ decade for pIRIR $_{290}$ (e.g. Thiel et al., 2011; Stevens et al., 2011; Murray et al., 2014; Balescu et al., 2020) and suggested that such low values are laboratory artefacts and do not reflect the instability of the signal in natural conditions (e.g. Thiel et al., 2011; Buylaert et al., 2012; Avram et al., 2020). Similar

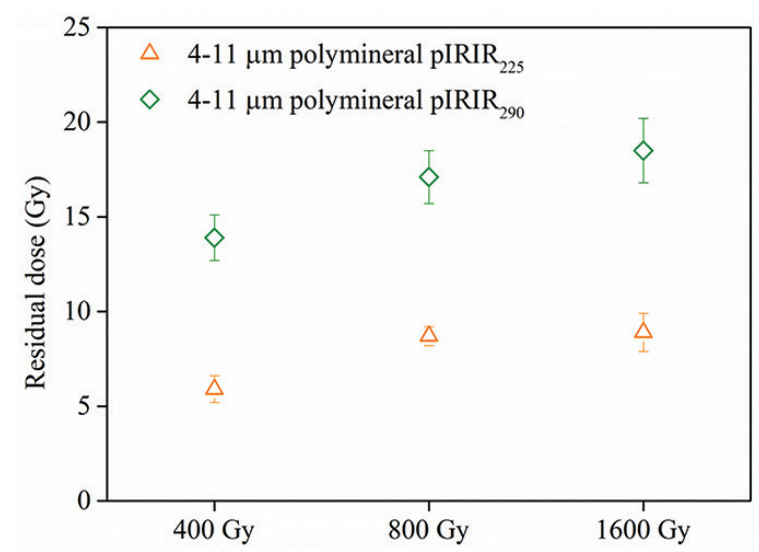

Fig 8. Residual dose as a function of previously given dose. pIRIR, postinfrared-infrared protocol.

Table 3. Summary of the pIRIR ${ }_{225}$ and pIRIR ${ }_{290}$ ages.

\begin{tabular}{|c|c|c|c|c|c|c|c|c|c|c|c|}
\hline \multirow{2}{*}{$\begin{array}{l}\text { Sample } \\
\text { code }\end{array}$} & \multirow{2}{*}{$\begin{array}{l}\text { Depth } \\
(\mathrm{cm})\end{array}$} & \multicolumn{2}{|c|}{ ED (Gy) } & \multicolumn{3}{|c|}{ Specific activities (Bq/kg) } & \multirow{2}{*}{$\begin{array}{c}\begin{array}{c}\text { Total dose rate } \\
\left(\text { Gy ka }^{-1}\right)\end{array} \\
\text { pIRIR }_{225 / 290} \text { pfg } \\
\end{array}$} & \multicolumn{2}{|c|}{ Ages $(k a)^{(1)}$} & \multicolumn{2}{|c|}{ Ages $(\mathrm{ka})^{(2)}$} \\
\hline & & pIRIR $_{225}$ pfg & pIRIR $_{290}$ pfg & $\mathrm{K}-40$ & Ra-226 & Th-232 & & pIRIR $_{225}$ pfg & pIRIR $_{290}$ pfg & pIRIR $_{225}$ pfg & pIRIR $_{290}$ pfg \\
\hline NZ 2 & 30 & $57 \pm 2$ & $60 \pm 4$ & $635 \pm 17$ & $36 \pm 1$ & $39 \pm 1$ & $4.2 \pm 0.1$ & $14 \pm 1$ & $14 \pm 1$ & $15 \pm 1$ & $18 \pm 2$ \\
\hline NZ 3 & 50 & $59 \pm 2$ & $63 \pm 4$ & $607 \pm 17$ & $27 \pm 2$ & $24 \pm 1$ & $3.4 \pm 0.1$ & $17 \pm 1$ & $18 \pm 2$ & $18 \pm 2$ & $24 \pm 2$ \\
\hline NZ 4 & 70 & $76 \pm 3$ & $100 \pm 7$ & $599 \pm 16$ & $26 \pm 1$ & $27 \pm 1$ & $3.4 \pm 0.1$ & $25 \pm 2^{(*)}$ & $29 \pm 3$ & $26 \pm 2^{(*)}$ & $32 \pm 3$ \\
\hline NZ 5 & 140 & $85 \pm 3$ & $91 \pm 6$ & $604 \pm 16$ & $35 \pm 1$ & $37 \pm 2$ & $4.0 \pm 0.1$ & $22 \pm 2$ & $25 \pm 3$ & $23 \pm 2$ & $28 \pm 3$ \\
\hline
\end{tabular}

(1)The residual dose estimated based on a modern analogue sample

${ }^{(2)}$ The residual dose measured after laboratory bleaching

${ }^{(*)}$ Indicates the age is corrected for fading 


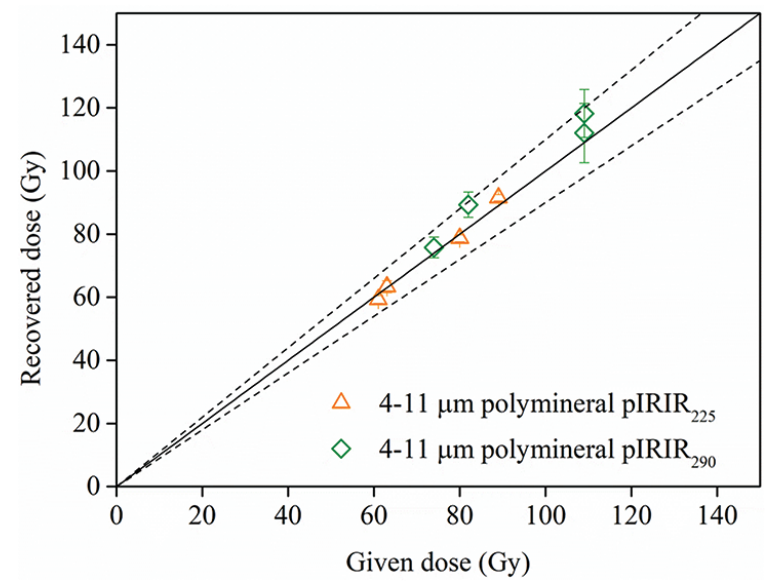

Fig 9. Dose recovery test results for polymineral fine grains using pIRIR ${ }_{225}$ (open triangles) and pIRIR (open diamonds) protocols. The given irradiation dose was chosen to match the equivalent dose of each sample. The solid line indicates the ideal 1:1 dose-recovery ratio while the dashed lines bracket a 10\% variation from unity.

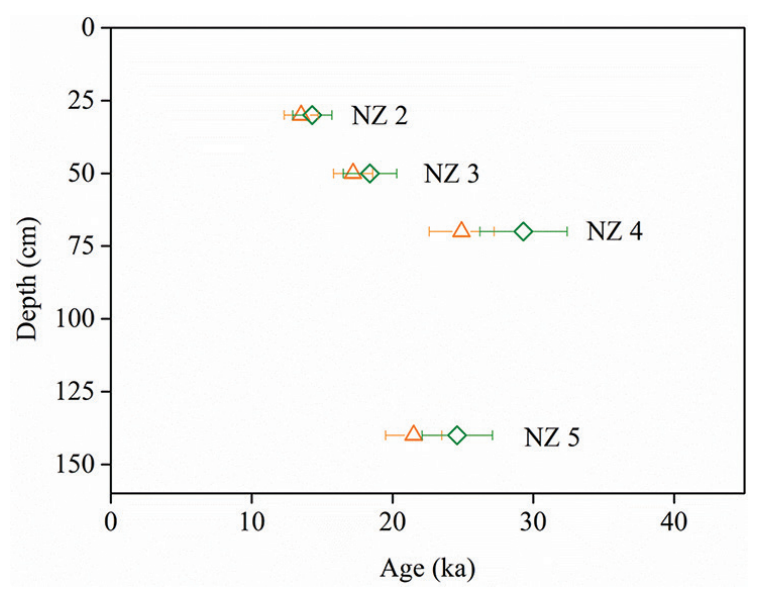

Fig 10. $p I R I R_{225}$ (open triangles) and pIRIR cence-ages plotted as function of depth. pIRIR, post-infraredinfrared protocols.

low fading rates have been reported on K-feldspars extracted from palaeo-rockfall boulders and loess from Banks Peninsula, South Island, New Zealand (Sohbati et al., 2016).

On the other hand, in the case of pIRIR $_{225}$ signals, it remains debatable whether the signals are affected by fading. Some studies reported g-values $>1 \% /$ decade (Buylaert et al., 2009; Zhang et al., 2018) while other works reported fading rates of $<1 \% /$ decade (Vasiliniuc et al., 2012; Avram et al., 2020). Therefore, the stability of the pIRIR ${ }_{225}$ signal was checked by an anomalous fading test performed on three 4-11 $\mu \mathrm{m}$ polymineral fine grain aliquots of samples NZ 2, NZ 4 and NZ 5 (Table S5 in Supplementary Material). The fading measurements were carried out on the same aliquots previously used in the dose recovery test. Each 4-11 $\mu \mathrm{m}$ polymineral aliquot was irradiated with a beta dose of $100 \mathrm{~Gy}$. A test dose of 17 Gy was used. Four consecutive prompt reads-out were carried out prior to storage. The aliquots were preheated before storage. The maximum time delay was 38 days ( $912 \mathrm{~h}$ ). Three consecutive prompt measurements were employed after the read-out corresponding to the longest storage time (Fig. S4 in Supplementary Material presents individual results obtained on all aliquots). A fading rate $<1 \%$ /decade was obtained for sample NZ 2 and NZ 5 , while for sample NZ 4 a g-value of $2.28 \pm 0.44 \% /$ decade was obtained. Therefore, the $\mathrm{pIRIR}_{225}{ }^{-}$and $\mathrm{pIRIR}_{290}$-ages presented in this study are not corrected for fading, except for sample NZ 4, for which a fading correction using the R Luminescence-package (Dietze et al., 2013) according to Huntley and Lamothe (2001) method was carried out.

\section{Luminescence Ages}

Luminescence ages obtained based on pIRIR protocolsalong with the dosimetry information-are presented in Table 3.

Only the ages obtained by residual dose correction using the modern analogue technique are represented as function of depth in Fig. 10. The pIRIR 225 -ages range from $14 \pm 1 \mathrm{ka}$ to $25 \pm 2 \mathrm{ka}$; on the other hand, the $\mathrm{pIRIR}_{290}$-ages are slightly higher than $\mathrm{pIRIR}_{225}$-ages, but still in agreement within errors for all samples. The pIRIR ${ }_{290}$-ages vary between $14 \pm 1 \mathrm{ka}$ and $29 \pm 3 \mathrm{ka}$.

The pIRIR-ages increase down-section, except for an age reversal between the sample NZ 4 and NZ 5. Such age reversals have been previously reported by others in the Canterbury region (e.g. Berger et al., 2001; Almond et al., 2007; Rowan et al., 2012). The ages suggest that loess from this site was deposited during the last glacial maximum of the Otira glaciation that occurred during 1824 ka (Alloway et al., 2007).

\section{Summary and Conclusions}

The difficulty of obtaining reliable luminescence chronologies for loess in New Zealand South Island is well known. In this context, the applicability of SAR-OSL protocol on quartz as well as the feldspar-SAR-based IRIR $_{225}$ and pIRIR $_{290}$ protocols on polymineral fine grains was investigated on four loess samples collected from the Southern Canterbury Plains. Although the purity and crystallinity of quartz extracts was confirmed by RAMAN spectroscopy, OSL signals displayed low sensitivity and significant sensitivity-change during the measurement cycles. It was shown that sensitisation of the OSL signal as well as that of the $110^{\circ} \mathrm{C} \mathrm{TL}$ peak could be achieved by annealing 
in the $300-500^{\circ} \mathrm{C}$ range, likely by the activation of luminescence centres. However, the same effect could not be achieved by repeated irradiation and bleaching cycles as previously suggested. While equivalent doses could not be securely obtained using quartz, the application of pIRIR $_{225}$ and pIRIR 290 methods were successful in achieving the following outcomes, namely: (i) dose recovery tests resulted in satisfactory results for both these protocols, results being consistent to unity at a $95 \%$ confidence level; (ii) fading rates of pIRIR 225 signals were generally negligible, with measured values of less than $1 \%$; (iii) although pIRIR $_{290}$ signals are more difficult to bleach than pIRIR $_{225}$ signals, constant residual values of $\cong 4$ and $\cong 10$ Gy were achieved after exposure under window light exposure for $48 \mathrm{~h}$ in the case of pIRIR $_{225}$ and $96 \mathrm{~h}$ in the case of pIRIR $_{290}$ signals, respectively; and (iv) a dependence of the residual on the previous given dose was observed; however, for a dose as large as $1600 \mathrm{~Gy}$, the residuals obtained for the two methods are $\cong 9$ and $\cong 19 \mathrm{~Gy}$, respectively. Thus, the equivalent dose of the sample used in the bleaching experiment should not have a significant effect when the residual dose is determined by laboratory experiments. The ages obtained by the application of the two pIRIR protocols are generally in agreement, with values ranging from $14 \pm 1 \mathrm{ka}$ to $29 \pm 3 \mathrm{ka}$, suggesting that loess from the investigated site was deposited during the last glacial maximum.

\section{Acknowledgement}

D. Brezeanu acknowledges the financial support obtained from Babeș-Bolyai University in the form of a research scholarship for students. This project has received funding from the European Research Council (ERC) under the European Union's Horizon 2020 research and innovation programme (grant agreements No. 678106 (INTERTRAP) and No. 677898 (MARCAN)).

\section{Supplementary information}

Supplementary information are available online at: DOI: $10.2478 /$ geochr-2021-0005

\section{References}

Aitken MJ and Alldred JC, 1972. The assessment of error limits in thermoluminescent dating. Archaeometry 14: 257-267.

Aitken MJ, 1985. Thermoluminescence Dating. Academic Press, London: 360pp.

Almond PC, Moar NT and Lian OB, 2001. Reinterpretation of the glacial chronology of South Westland, New Zealand. New Zealand Journal of Geology and Geophysics 44(1): 1-15, DOI: 10.1080/00288306.2001.9514917.

Almond PC, Shanhun FL, Rieser U and Shulmeister J, 2007. An OSL, radiocarbon and tephra isochron-based chronology for Birdlings Flat loess at Ahuriri Quarry, Banks Peninsula, Canterbury, New Zealand. Quateranary Geochronology 2(1-4): 4-8, DOI: 10.1016/J.QUAGEO.2006.06.002.

Alloway BV, Pillans BJ, Sandhu AS and Westgate JA, 1993. Revision of the marine chronology in the Wanganui Basin, New Zealand, based on isothermal plateau fission-track dating of tephra horizons. Sedimentary Geology 82(1-4): 299-310, DOI: 10.1016/0037-0738(93)90128-R.

Alloway BV, Lowe DJ, Barrell DJ, Newnham RM, Almond PC, Augustinus PC, Bertler NA, Carter L, Litchfield NJ, McGlone MS, Shulmeister J, Vandergoes $\mathrm{M}$, Williams $\mathrm{P}$ and NZ-INTIMATE Members, 2007. Towards a climate event stratigraphy for New Zealand over the past 30,000 years (NZ-INTIMATE project). Journal of Quaternary Science 22(1): 9-35, DOI: 10.1002/JQS.1079.

Avram A, Constantin D, Veres D, Kelemen S, Obreht I, Hambach U, Marković SB and Timar-Gabor A, 2020. Testing polymineral
post-IR IRSL and quartz SAR-OSL protocols on Middle to Late Pleistocene loess at Batajnica, Serbia. Boreas 49(3): 615-633, DOI: 10.1111/bor.12442.

Balescu S, Jordanova D, Brisson LF, Hardy F, Huot S and Lamothe $M, 2020$. Luminescence chronology of the Northeastern Bulgarian loess-paleosol sequences (Viatovo and Kaolinovo). Quaternary International 552: 15-24, DOI: 10.1016/j. quaint.2019.04.020.

Bell DH and Trangmar BB, 1987. Regolith materials and erosion processes on the Port Hills, Christchurch, New Zealand. In: 5th International Conference \& Field Workshop on Landslides. Christchurch, pp. 93-105.

Berger GW, Pillans BJ and Tonkin PJ, 2001. Luminescence chronology of loess-paleosol sequences from Canterbury, South Island, New Zealand. New Zealand Journal of Geology and Gheophysics 44(4): 501-516, DOI: 10.1080/00288306.2001.9514952.

Berger GW, Pillans BJ, Bruce JG and McIntosh PD, 2002. Luminescence chronology of loess-paleosol sequences from southern South Island, New Zealand. Quaternary Science Reviews 21(1617): 1899-1913, DOI: 10.1016/S0277-3791(02)00021-5.

Borella J, Quigley M, Sohbati R, Almond P, Gravley DM and Murray A, 2016. Chronology and processes of late Quaternary hillslope sedimentation in the Eastern South Island, New Zealand. Journal of Quaternary Science 31(7): 691-712, DOI: 10.1002/JQS.2905.

Bøtter-Jensen L, Larsen NA, Mejdahl, V, Poolton NR, Morris, MF, McKeever, SW, 1995. Luminescence sensitivity changes in 
quartz as a result of annealing. Radiation Measurement 24(4): 535-541, DOI: 10.1016/1350-4487(95)00006-Z.

Buylaert JP, Murray AS and Thomsen KJ, 2009. Testing the potential of an elevated temperature IRSL signal from K-feldspar. Radiation Measurements 44(5-6): 560-565, DOI: 10.1016/J. RADMEAS.2009.02.007.

Buylaert JP, Huot S, Murray AS and Van Den Haute P, 2011a. Infrared stimulated luminescence dating of an Eemian (MIS 5e) site in Denmark using K-feldspar. Boreas 40(1): 46-56, DOI: 10.1111/J.1502-3885.2010.00156.X.

Buylaert JP, Thiel C, Murray A, Vandenberghe D, Yi S and Lu H, 2011b. IRSL and post-IR IRSL residual doses recorded in modern dust samples from the Chinese loess plateau. Geochronometria 38(4): 432-440, DOI: 10.2478/s13386011-0047-0.

Buylaert JP, Jain M, Murray AS, Thomsen KJ, Thiel C and Sohbati $R, 2012$. A robust feldspar luminescence dating method for Middle and Late Pleistocene sediments. Boreas 41(3): 435-451, DOI: 10.1111/J.1502-3885.2012.00248.X.

Campbell IB, 1986. New occurrences and distribution of Kawakawa Tephra in South Island, New Zealand. New Zealand Journal of Geology and Geophysics 29(4): 425-435, DOI: 10.1080/00288306.1986.10422164.

Chruścińska A, Oczkowski HL, Przegiętka K, 1996. Trap spectra of annealed quartz. Acta Physica Polonica A 4(89): 555-568. http://repozytorium.umk.pl/handle/item/1917.

Dietze M, Kreutzer S, Fuchs MC, Burrow C, Fischer M and Schmidt C, 2013. A practical guide to the R package luminescence. Ancient TL 31(1): 11-18.

Duller GA, 2003. Distinguishing quartz and feldspars in single grain luminescence measurements. Radiation Measurements 37(2): 161-165, DOI: 10.1016/S1350-4487(02)00170-1.

Eden DN, Froggatt PC and Mclntosh PD, 1992. The distribution and composition of volcanic glass in late Quaternary loess deposits of Southern South Island, New Zealand, and some possible correlations. New Zealand Journal of Geology and Geophysics 35(1): 69-79, DOI: 10.1080/00288306.1992.9514501.

Eden DN and Hammond AP, 2003. Dust accumulation in the New Zealand region since the last glacial maximum. Quaternary Science Reviews 22(18-19): 2037-2052, DOI: 10.1016/ S0277-3791(03)00168-9.

Frechen M, Schweitzer $\mathrm{U}$ and Zander A, 1996. Improvements in sample preparation for the fine grain technique. Ancient $T L$ 14(2): 15-17.

Goh KM, Tonkin PJ and Rafter TA, 1978. Implications of improved radiocarbon dates of Timaru peats on Quaternary loess stratigraphy. New Zealand Journal of Geology and Geophysics 21(4): 463-466, DOI: 10.1080/00288306.1978.10424071.

Guérin G, Mercier N and Adamiec G, 2011. Dose-rate conversion factors: Update. Ancient TL 29(1): 5-8.

Guralnik B, Ankjærgaard C, Jain M, Murray AS, Müller A, Wälle M, Lowick SE, Preusser F, Rhodes EJ, Wu TS, Mathew G, Her- man F, 2015. OSL-thermochronometry using bedrock quartz: A note of caution. Quaternary Geochronology 25: 37-48, DOI: 10.1016/j.quageo.2014.09.001.

Hammond AP, Goh KM, Tonkin PJ and Manning MR, 1991. Chemical pretreatments for improving the radiocarbon dates of peats and organic silts in a gley podzol environment: Grahams Terrace, North Westland. New Zealand Journal of Geology and Geophysics 34(2): 191-194, DOI: 10.1080/00288306.1991.9514456.

Hansen V, Murray A, Buylaert JP, Yeo EY and Thomsen K, 2015. A new irradiated quartz for beta source calibration. Radiation Measurements 81: 123-127, DOI: 10.1016/J.RADMEAS.2015.02.017.

Holdaway RN, Roberts RG, Beavan-Athfield NR, Olley JM and Worthy TH, 2002. Optical dating of quartz sediments and accelerator mass spectrometry $14 \mathrm{C}$ dating of bone gelatin and moa eggshell: A comparison of age estimates for non-archaeological deposits in New Zealand. Journal of the Royal Society of New Zealand 32(3): 463-505, DOI: 10.1080/03014223.2002.9517705.

Hormes A, Preusser F, Denton G, Hajdas I, Weiss D, Stocker TF and Schlüchter C, 2003. Radiocarbon and luminescence dating of overbank deposits in outwash sediments of the Last Glacial Maximum in North Westland, New Zealand. New Zealand Journal of Geology and Geophysics 46(1): 95-106, DOI: 10.1080/00288306.2003.9514998.

Huntley DJ and Lamothe M, 2001. Ubiquity of anomalous fading in K-feldspars and the measurement and correction for it in optical dating. Canadian Journal of Earth Sciences 38(7): 1093-1106, DOI: 10.1139/E01-013.

Kohn BP, Pillans B and McGlone MS, 1992. Zircon fission track age for middle Pleistocene Rangitawa Tephra, New Zealand: Stratigraphic and paleoclimatic significance. Palaeogeography, Palaeoclimatology, Palaeoecology 95(1-2): 73-94, DOI: 10.1016/0031-0182(92)90166-3.

Krishnan RS, 1945. Raman spectrum of quartz. Nature 155(3937): 452, DOI: 10.1038/155452a0.

Lang A, Lindauer S, Kuhn R and Wagner GA, 1996. Procedures used for optically and infrared stimulated luminescence dating of sediments in Heidelberg. Ancient TL 14(3): 7-11.

Lapp T, Kook M, Murray AS, Thomsen KJ, Buylaert JP and Jain M, 2015. A new luminescence detection and stimulation head for the Ris $\varnothing$ TL/OSL reader. Radiation Measurements 81: 178184, DOI: 10.1016/J.RADMEAS.2015.02.001.

Litchfield NJ and Lian OB, 2004. Luminescence age estimates of Pleistocene marine terrace and alluvial fan sediments associated with tectonic activity along coastal Otago, New Zealand. New Zealand Journal of Geology and Geophysics 47(1): 29-37, DOI: 10.1080/00288306.2004.9515035.

Litchfield NJ and Rieser U, 2005. Optically stimulated luminescence age constraints for fluvial aggradation terraces and loess in the Eastern North Island, New Zealand. New Zea- 
land Journal of Geology and Geophysics 48(4): 581-589, DOI: 10.1080/00288306.2005.9515135.

Martini M, Fasoli M and Villa, I, 2014. Defect studies in quartz: Composite nature of the blue and UV emissions. Nuclear Instruments and Methods in Physics Research B, 327: 15-21, DOI 10.1016/J.NIMB.2013.09.048.

Murray AS, 1996. Developments in optically stimulated luminescence and photo-transferred thermoluminescence dating of young sediments: Application to a 2000-years of flood deposits. Geochimica et Cosmochimica Acta 60(4): 565-576, DOI: 10.1016/0016-7037(95)00418-1.

Murray AS and Wintle AG, 2000. Luminescence dating using an improved single-aliquot regenerative-dose protocol. Radiation Measurements 32: 57-73, DOI: 10.1016/S13504487(99)00253-X.

Murray AS and Wintle AG, 2003. The single aliquot regenerative dose protocol: Potential for improvements in reliability. Radiation Measurements 37(4-5): 377-381, DOI: 10.1016/S13504487(03)00053-2.

Murray AS, Thomsen KJ, Masuda N, Buylaert JP and Jain M, 2012. Identifying well-bleached quartz using the different bleaching rates of quartz and feldspar luminescence signals. Radiation Measurements 47(9): 688-695, DOI: 10.1016/J.RADMEAS.2012.05.006.

Murray AS, Schmidt ED, Stevens T, Buylaert JP, Marković SB, Tsukamoto $S$ and Frechen M, 2014. Dating middle pleistocene loess from Stari Slankamen (Vojvodina, Serbia) - Limitations imposed by the saturation behaviour of an elevated temperature IRSL signal. Catena 117: 34-42, DOI: 10.1016/J.CATENA.2013.06.029.

Nichol SL, Lian OB and Carter CH, 2003. Sheet-gravel evidence for a late Holocene tsunami run-up on beach dunes, Great Barrier Island, New Zealand. Sedimentary Geology 155(1-2): 129-145, DOI: 10.1016/S0037-0738(02)00191-4.

Pillans B, 1991. New Zealand Quaternary stratigraphy: An overview. Quaternary Science Reviews 10(5): 405-418, DOI: 10.1016/0277-3791(91)90004-E.

Pillans B, 1994. Direct marine-terrestrial correlations, Wanganui Basin, New Zealand: The last 1 million years. Quaternary Science Reviews 13(3): 189-200, DOI: 10.1016/02773791(94)90024-8.

Pillans B, Kohn BP, Berger G, Froggatt P, Duller G, Alloway B and Hesse $P, 1996$. Multi-method dating comparison for mid-Pleistocene Rangitawa Tephra, New Zealand. Quaternary Science Reviews (Quaternary Geochronology) 15(7): 641-654, DOI: 10.1016/0277-3791(96)00035-2.

Prescott JR and Hutton JT, 1994. Cosmic ray contributions to dose rates for luminescence and ESR dating: Large depths and long-term variations. Radiation Measurements 23: 497-500, DOI: 10.1016/1350-4487(94)90086-8.

Preusser F, Andersen BG, Denton GH and Schlüchter C, 2005. Luminescence chronology of Late Pleistocene glacial deposits in North Westland, New Zealand. Quaternary Science
Reviews 24(20-21): 2207-2227, DOI: 10.1016/J.QUASCIREV.2004.12.005.

Preusser F, Ramseyer K and Schlüchter C, 2006. Characterisation of low OSL intensity quartz from the New Zealand Alps. Radiation Measurements 41(7-8): 871-877, DOI: 10.1016/J.RADMEAS.2006.04.019.

Preusser F, Chithambo ML, Götte T, Martini M, Ramseyer K, Sendezera EJ, Susino GJ, Wintle AG, 2009. Quartz as a natural luminescence dosimeter. Earth Science Reviews 97(1/4): 184-214. DOI: 10.1016/j.earscirev.2009.09.006.

Raeside JD, 1964. Loess deposits of the South Island, New Zealand, and soils formed on them. New Zealand Journal of Geology and Geophysics 7(4): 811-838, DOI: 10.1080/00288306.1964.10428132.

Rees-Jones J, 1995. Optical dating of young sediments using finegrain quartz. Ancient TL 13(2): 9-13.

Rother H, Shulmeister J and Rieser U, 2009. Stratigraphy, optical dating chronology (IRSL) and depositional model of pre-LGM glacial deposits in the Hope Valley, New Zealand. Quaternary Science Reviews, 1-17, DOI: 10.1016/J.QUASCIREV.2009.11.001.

Rowan AV, Roberts HM, Jones MA, Duller GA, Covey-Crump SJ and Brocklehurst $\mathrm{SH}, 2012$. Optically stimulated luminescence dating of glaciofluvial sediments on the Canterbury Plains, South Island, New Zealand. Quaternary Geochronology 8: 10-22, DOI: 10.1016/J.QUAGEO.2011.11.013.

Schilles T, Poolton NRJ, Bulur EN, Bøtter-Jensen L, Murray AS, Smith GM, Riedi PC and Wagner GA, 2001. A multi-spectroscopic study of luminescence sensitivity changes in natural quartz induced by high-temperature annealing. Journal of Physics D 34(5): 722-731, DOI: 10.1088/0022-3727/34/5/310.

Shulmeister J, Thackray GD, Rieser U, Hyatt OM, Rother H, Smart CC and Evans DJ, 2010. The stratigraphy, timing and climatic implications of glaciolacustrine deposits in the middle Rakaia Valley, South Island, New Zealand. Quaternary Science Reviews 29(17-18): 2362-2381, DOI: 10.1016/J.QUASCIREV.2010.06.004.

Sohbati R, Murray AS, Buylaert JP, Ortuno M, Cunha PP and Masana $E$, 2012. Luminescence dating of Pleistocene alluvial sediments affected by the Alhama de Murcia fault (eastern Betics, Spain) - A comparison between OSL, IRSL and postIR IRSL ages. Boreas 41(2): 250-262, DOI: 10.1111/J.15023885.2011.00230.X.

Sohbati R, Borella J, Murray A, Quigley M and Buylaert JP, 2016. Optical dating of loessic hillslope sediments constrains timing of prehistoric rockfall, Christchurch, New Zealand. Journal of Quaternary Science 31(7): 678-690, DOI: 10.1002/JQS.2895.

Sparrow CL, 1948. Loess Deposits of Banks Peninsula. Unpublished MA Thesis University of New Zealand.

Stevens T, Marković SB, Zech M, Hambach U and Sümegi P, 2011. Dust deposition and climate in the Carpathian Basin over an independently dated last glacial-interglacial cycle. Quaternary Science Reviews 30(5-6): 662-681, DOI: 10.1016/J.QUASCIREV.2010.12.011. 
Suggate RP, 1990. Late pliocene and quaternary glaciations of New Zealand. Quaternary Science Reviews 9(2-3): 175-197, DOI: 10.1016/0277-3791(90)90017-5.

Thiel C, Buylaert JP, Murray A, Terhorst B, Hofer I, Tsukamoto S and Frechen $\mathrm{M}, 2011$. Luminescence dating of the Stratzing loess profile (Austria) - Testing the potential of an elevated temperature post-IR IRSL protocol. Quaternary International 234(1-2): 23-31, DOI: 10.1016/J.QUAINT.2010.05.018.

Thomsen K, Murray A and Jain M, 2011. Stability of IRSL signals from sedimentary K-feldspar samples. Geochronometria 38(1): 1-13, DOI: 10.2478/s13386-011-0003-z.

Toyoda S, Hattori W, 2000. Formation and decay of the E1' center and of its precursor. Applied Radiation and Isotopes 52(5): 1351-1356. DOI: 10.1016/S0969-8043(00)00094-4.

Vasiliniuc Ș, Vandenberghe DA, Timar-Gabor A, Panaiotu C and Cosma C, 2012. Testing the potential of elevated temperature post-IR IRSL signals for dating Romanian loess. Quaternary Geochronology 10: 75-80, DOI: 10.1016/J.QUAGEO.2012.02.014.

Veres D, Tecsa V, Gerasimenko N, Zeeden C, Hambach U and Timar-Gabor A, 2018. Short-term soil formation events in last glacial east European loess, evidence from multi-method luminescence dating. Quaternary Science Reviews 200: 34-51, DOI: 10.1016/J.QUASCIREV.2018.09.037.

Veronese I, Giussani A, Goksu HY, Martini M, 2004. The trap parameters of electrons in intermediate energy levels in quartz. Radiation Measurements 38(4-6): 743-746, DOI: 10.1016/j. radmeas.2004.01.012.

Wacha L and Frechen M, 2011. The geochronology of the "Gorjanović loess section" in Vukovar, Croatia. Quaternary International 240(1-2): 87-99, DOI: 10.1016/J. QUAINT.2011.04.010.
Wallinga J, Murray A and Duller G, 2000. Underestimation of equivalent dose in single-aliquot optical dating of feldspars caused by preheating. Radiation Measurements 32(5-6): 691-695, DOI: 10.1016/S1350-4487(00)00127-X.

Wilson CJ, Switsur VR and Ward AP, 1988. A new 14C age for the Oruanui (Wairakei) eruption, New Zealand. Geological Magazine 125(3): 296-300, DOI: 10.1017/S0016756800010232.

Yang XH and McKeever SW, 1990. The pre-dose effect in crystalline quartz. Journal of Physics D 23(2): 237-244, DOI: 10.1088/0022-3727/23/2/017.

Yates K, Fenton CH and Bell DH, 2018. A review of the geotechnical characteristics of loess and loess-derived soils from Canterbury, South Island, New Zealand. Engineering Geology 236: 11-21, DOI: 10.1016/J.ENGGEO.2017.08.001.

Yi S, Buylaert JP, Murray AS, Lu H, Thiel C and Zeng L, 2016. A detailed post-IR IRSL dating study of the Niuyangzigou loess site in northeastern China. Boreas 45(4): 644-657, DOI: 10.1111/ BOR.12185.

Yi S, Li X, Han Z, Lu H, Liu J and Wu J, 2018. High resolution luminescence chronology for Xiashu Loess deposits of Southern China. Journal of Asian Earth Sciences 155: 188-197, DOI: 10.1016/J.JSEAES.2017.11.027.

Young DJ, 1964. Stratigraphy and petrography of North-East Otago Loess. New Zealand Journal of Geology and Geophysics 7(4): 839-863, DOI: 10.1080/00288306.1964. 10428133.

Zhang J, Rolf C, Wacha L, Tsukamoto S, Durn G and Frechen M, 2018. Luminescence dating and palaeomagnetic age constraint of a last glacial loess-paleosol sequence from Istria, Croatia. Quaternary International 494: 19-33, DOI: 10.1016/J. QUAINT.2018.05.045. 